\title{
Case Study of Integrating an Offshore Wind Farm with Offshore Oil and Gas Platforms and with an Onshore Electrical Grid
}

\author{
Wei He, ${ }^{1}$ Kjetil Uhlen, ${ }^{2}$ Mahesh Hadiya, ${ }^{2}$ Zhe Chen, ${ }^{3}$ Gang Shi, ${ }^{3}$ and Emilio del Rio ${ }^{3}$ \\ ${ }^{1}$ Research Centre, Statoil ASA, Sandsliveien 90, 5020 Bergen, Norway \\ ${ }^{2}$ Department of Electrical Engineering, Norwegian University of Science and Technology, Realfagbygget D3, 7491 Trondheim, Norway \\ ${ }^{3}$ Department of Energy Technology, Aalborg University, Pontoppidanstrcede 101, 9220 Aalborg, Denmark
}

Correspondence should be addressed to Wei He; weih@statoil.com

Received 7 November 2012; Accepted 27 March 2013

Academic Editor: Surya Santoso

Copyright (C) 2013 Wei He et al. This is an open access article distributed under the Creative Commons Attribution License, which permits unrestricted use, distribution, and reproduction in any medium, provided the original work is properly cited.

\begin{abstract}
This research project explored the technical feasibility of utilizing an offshore wind farm as a supplementary power source to several electrical grids of offshore oil and gas platforms and providing surplus power to an onshore grid. Three case studies comprising wind farms rated at $20 \mathrm{MW}, 100 \mathrm{MW}$, and $1000 \mathrm{MW}$ have been studied with the focus on (i) the operation benefits of $\mathrm{CO}_{2} / \mathrm{NO}_{x}$ emission reduction, (ii) the electrical grid stability, and (iii) the technical implementation feasibility. The proposed $20 \mathrm{MW}, 100 \mathrm{MW}$, and $1000 \mathrm{MW}$ wind farm cases are theoretically feasible in terms of the selected technical criteria, although further detailed design operational studies, and economical analysis are required.
\end{abstract}

\section{Introduction}

The successful pilot operation of Statoil's floating Hywind 2.3 MW wind turbine unit has proven the new technology to capture wind energy within deep water environments. It has also demonstrated the potential to utilize the excellent wind resource nearby offshore oil and gas platforms where the water depth is from a hundred to several hundred meters.

An offshore oil and gas platform often consists of many energy consuming facilities including drilling, accommodation, processing, exporting, and injection. The current electrical power consumption at a platform on Norwegian Continental Shelf (NCS) is often in the range from $10 \mathrm{MW}$ to several hundreds of MW. The NCS is a mature petroleum province and the energy consumption per produced unit will grow. Offshore platforms are facing increasingly tougher challenges to operate in an environmentally acceptable manner. Most platforms on NCS generate their own electrical power by gas turbines. The gas turbines are also used to directly drive compressors and pumps. These gas turbines generate about $80 \%$ of the total $\mathrm{CO}_{2}$ and $\mathrm{NO}_{x}$ emissions from offshore installations [1].
Accordingly, this research project explored the technical feasibility of utilizing wind farms as a supplementary power source to offshore oil and gas platforms and to provide surplus power to an onshore grid.

\section{Three Study Cases}

Three case studies comprising wind farms rated at $20 \mathrm{MW}$, $100 \mathrm{MW}$, and $1000 \mathrm{MW}$ have focused on (i) the operation benefits of $\mathrm{CO}_{2} / \mathrm{NO}_{x}$ emission reduction, (ii) electrical grid stability, and (iii) the technical implementation feasibility.

The first case $(20 \mathrm{MW})$ is the integration of a small offshore wind farm with a stand-alone electrical grid on the offshore oil and gas platform. The second case (100 MW) is the extension of the first case. To utilize more wind power, a $100 \mathrm{MW}$ wind farm is connected to five nearby oil and gas platforms by subsea power cables. In order to achieve an economically feasible offshore wind farm, the third case (1000 MW wind farm) has been proposed for supplying the wind power both to the oil and gas platforms and to the onshore electrical grid. The description of these three cases is given in Table 1. 
TABLE 1: Three study cases.

Cases description

Case $1-20 \mathrm{MW}$ wind farm:

Four $5 \mathrm{MW}$ wind turbines generate electrical power in parallel with three gas turbines (each has capacity of $23 \mathrm{MW})$

\section{Objectives}

(i) Estimate the long-term operation benefits of wind power integration in terms of fuel savings and $\mathrm{CO}_{2} / \mathrm{NO}_{x}$ emissions reduction.

(ii) Determine the electrical grid stability due to the integration of four $5 \mathrm{MW}$ wind power generator units.

(iii) Identify the maximum amount of wind power possible to integrate to the stand-alone electrical grid on the offshore platform.

(i) Assess the maximum amount of wind power that can be integrated to each platform.

(ii) Electrical grid stability in terms of the control strategy and interconnecting grid topology.

(i) Design the electrical grid layout.

(ii) Calculate the transmission losses.

(iii) Evaluate the electrical grid stability.

TABLE 2: The simulated yearly fuel consumption and emissions.

\begin{tabular}{lcccccc}
\hline Operation strategy & \multirow{2}{*}{ Wind (MW) } & \multicolumn{3}{c}{ Simulation results } & \multicolumn{2}{c}{ Reduction due to wind power } \\
$\mathrm{CO}_{2}$ (tonnes) & $\mathrm{NO}_{x}$ (tonnes) \\
\hline- & 0 & 61 & 134100 & 914 & & \\
Equal load & 20 & 43 & 94380 & 644 & 18 & 39720 \\
Start/stop & 20 & 37 & 80310 & 548 & 24 & 53790 \\
\hline
\end{tabular}

TABLE 3: Nine dynamic simulation cases.

\begin{tabular}{lc}
\hline Contingency scenarios & Operation modes \\
\hline $\begin{array}{l}\text { A: Online start of one } \\
\text { large induction motor }\end{array}$ & A2: 1 gas turbine + 2 wind turbine: $10 \mathrm{MW}$ \\
\hline $\begin{array}{l}\text { B: Loss of one gas } \\
\text { turbine production }\end{array}$ & B1: 2 gas turbine + 2 wind turbine: $10 \mathrm{MW}$ \\
& B2: 2 gas turbine + 4 wind turbine: $20 \mathrm{MW}$ \\
\hline C: Loss of all wind & C1: 1 gas turbine + 2 wind turbine: $10 \mathrm{MW}$ \\
turbines & C2: 2 gas turbine + 4 wind turbine: $10 \mathrm{MW}$ \\
& C3:2 gas turbine + 4 wind turbine: $10 \mathrm{MW}$ \\
\hline D: Wind fluctuations & A2: 1 gas turbine + 4 wind turbine: $10 \mathrm{MW}$ \\
& A2: 2 gas turbine + 4 wind turbine: $10 \mathrm{MW}$ \\
\hline
\end{tabular}

\section{Simulation Implementation}

3.1. Simulation Models for Case 1-20 MW Wind Farm. The potential fuel gas saving and $\mathrm{CO}_{2} / \mathrm{NO}_{x}$ emission reductions due to wind power integration were simulated by a model implemented in MATLAB. The inputs were a series of wind speeds and power consumptions on the platform over time. The simulated fuel gas consumption and $\mathrm{CO}_{2}$ emissions were compared to the real data from an offshore platform.

The dynamic simulation models were implemented in SIMPOW [2], and it included both the platform electrical grids models and the wind farm models. The dynamic simulation models were achieved by modifying the short circuit calculation models of the platforms. Four $5 \mathrm{MW}$ wind turbine units were added to the short circuit calculation models. Each wind turbine was modeled using the full power converter wind turbine (FPCWT) model described in the
SIMPOW manual [2]. An illustration of the wind turbine model is given in Figure 1.

The simulated frequency and voltage variations were compared with the NORSOK standard [4] for power quality requirements on offshore installations. The additional simulations were run to determine the maximum amount of wind power possible to integrate into the platform. The technical limit is defined by the load level, the NORSOK standard of the frequency and voltage variations, and the wind-power strategy during platform operations.

3.2. Simulation Models for Case 2-100 MW Wind Farm. The simulation models of the $100 \mathrm{MW}$ case have been implemented both in EMTDC/PSCAD [5] and in SIMPOW [2] by two research groups, respectively $[3,6]$.

The goal of the $100 \mathrm{MW}$ simulation model in PSCAD is to identify the maximum amount of wind power for the integration with each platform. The gas turbine, synchronous generator, and the wind turbine models in PSCAD have been tested by comparing the results from the models in SIMPOW [2]. The four main modules in the $5 \mathrm{MW}$ wind turbine model in PSCAD are wind source, wind turbine, wind turbine governor, and generator, all illustrated in Figure 2. The module of wind turbine has inputs of the wind speed from the wind source module and the wind speed at the hub height, while the outputs are the mechanical torque transmitted to the generator and the power from the wind turbine. The module of wind turbine governor has the blade pitch control. The inputs are the mechanical power of the wind turbine and also the speed of the hub, while the output is the blade pitch angel.

The $100 \mathrm{MW}$ simulation model in SIMPOW is the extension of the $20 \mathrm{MW}$ simulation model [7] by including four 
TABLE 4: Frequency/voltage deviations $(\Delta f / \Delta V)$ during loss of all wind power.

C1: 1 gas turbine +2 wind turbine: $10 \mathrm{MW}$, load: $19 \mathrm{MW}$

$\Delta f=4.5 \%, \Delta V=1.5 \%$

C2: 2 gas turbine +4 wind turbine: $20 \mathrm{MW}$, load: $35 \mathrm{MW}$

$\Delta f=4.6 \%, \Delta V=1.5 \%$

$\mathrm{C} 1$ : 1 gas turbine +4 wind turbine: $20 \mathrm{MW}$, load: $25 \mathrm{MW}$

$\Delta f=7.3 \%^{*}, \Delta V=1.7 \%$

${ }^{*}$ NORSOK frequency transient requirement: $5 \%$.

TABLE 5: Maximum wind power for integration to each platform individually.

\begin{tabular}{lcccc}
\hline Platform number & Main electrical power generation & Main bus & $\begin{array}{c}\text { Maximum wind power } \\
\text { (1 GT connected) }\end{array}$ & $\begin{array}{c}\text { Maximum wind power } \\
(2 \mathrm{GT} \text { connected) }\end{array}$ \\
\hline Platform 1 & $3 * 23 \mathrm{MW}+19.4 \mathrm{MW}$ & $13.8 \mathrm{kV}, 60 \mathrm{~Hz}$ & $10 \mathrm{MW}$ & $19 \mathrm{MW}$ \\
Platform 2 & $2 * 22 \mathrm{MW}$ & $11 \mathrm{kV}, 50 \mathrm{~Hz}$ & $9 \mathrm{MW}$ & $17.6 \mathrm{MW}$ \\
Platform 3 & $2 * 22 \mathrm{MW}$ & $11 \mathrm{kV}, 50 \mathrm{~Hz}$ & $10 \mathrm{MW}$ & $17 \mathrm{MW}$ \\
Platform 4 & $2 * 24.8 \mathrm{MW}$ & $11 \mathrm{kV}, 50 \mathrm{~Hz}$ & $11 \mathrm{MW}$ & $20 \mathrm{MW}$ \\
Platform 5 & $24 \mathrm{MW}$ & $11 \mathrm{kV}, 50 \mathrm{~Hz}$ & $9 \mathrm{MW}$ & $9 \mathrm{MW}^{*}$ \\
\hline Total & & $49 \mathrm{MW}$ & $82.6 \mathrm{MW}$ \\
\hline
\end{tabular}

${ }^{*}$ There is only one gas turbine on platform 5 .

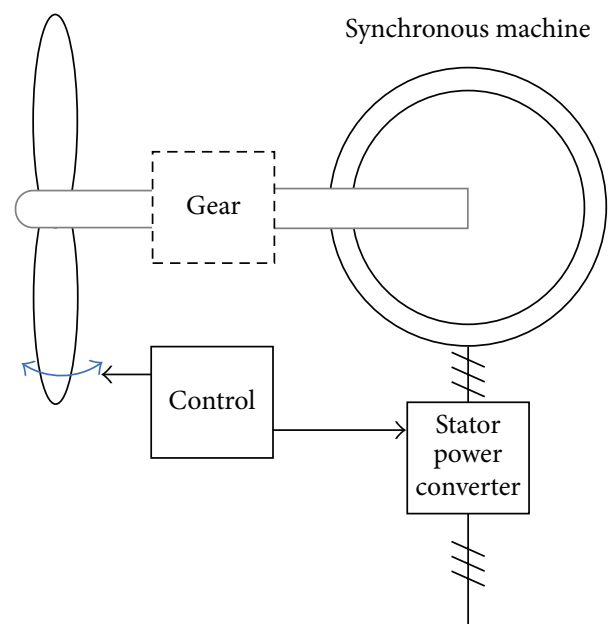

FIgURE 1: Wind turbine model in SIMPOW [2].

more platforms illustrated in Figure 3. The electrical grid stability was analysed based on three different topologies of the five platforms shown in Figure 4.

\subsection{Simulation Models for Case 3-1000 MW Wind Farm.}

The $1000 \mathrm{MW}$ wind farm case is illustrated in Figure 5. Platform A has current electrical load of $100 \mathrm{MW}$ and the electrical power is supplied from onshore via one AC sea cable and two DC sea cables. The electrical load at Platform A will increase from $100 \mathrm{MW}$ to $200 \mathrm{MW}$. The new sea cables have been planned in order to provide more electrical power from onshore to Platform A. This $1000 \mathrm{MW}$ case provides an alternative to supply the wind power to Platform A and the surplus wind power to the onshore electrical grid.

As shown in Figure 5, there are one AC and two DC transmission lines in existence. There is a plan to build one new AC and two new DC transmission lines in the year 2015. Accordingly, one proposal of the $1000 \mathrm{MW}$ offshore wind farm integration is shown in Figure 6. The $1000 \mathrm{MW}$ simulation model was implemented in PSCAD [8], and it consists of offshore wind farm, oil and gas platform, HVAC, HVDC, and onshore grid modules.

The simulation results of the three study cases are summarized as follows.

\section{Simulation Results of Case $1-20$ MW Wind Farm}

The simulated yearly fuel consumption and $\mathrm{CO}_{2} / \mathrm{NO}_{x}$ emissions and the reduction due to wind power are given in Table 2. In the case at average load of $30.6 \mathrm{MW}$, the simulation results show that the integration of a $20 \mathrm{MW}$ wind farm to an offshore platform would achieve approximately a $40 \%$ reduction in fuel gas and $\mathrm{CO}_{2} / \mathrm{NO}_{x}$ emissions when one gas turbine can be started and stopped. The yearly case would result in an annual reduction of 53,790 tonnes of $\mathrm{CO}_{2}$ and 366 tonnes of $\mathrm{NO}_{x}$.

The simulation results also show that the gas turbine start/stop operating strategy would result in a further annual reduction of $6 \mathrm{Msm}^{3}$ of fuel gas, 14,070 tonnes of $\mathrm{CO}_{2}$, and 96 tonnes of $\mathrm{NO}_{x}$. This further reduction is due to the gas turbine efficiency increase from $25.6 \%$ to $30.1 \%$. The penalty is that the second gas turbine must be switched off and started 543 times during the year, that is, approximately 1.5 times per day. Further study is needed to assess the possible mechanical degradation and lifespan reduction of the gas turbine and the operational risks due to the additional motor starts and stops. The simulated fuel gas consumption and $\mathrm{CO}_{2}$ emissions agree with the real platform's operation data.

The electrical grid stability after integration of a $20 \mathrm{MW}$ wind power generator was tested by nine cases under four contingency scenarios listed in Table 3 . The variations in frequency and voltage due to wind fluctuations are much smaller than the first three disturbances. The added wind power reduces the voltage and frequency variations during a motor start. The loss of all wind power became critical when the amount of wind power integration is increased, and this 


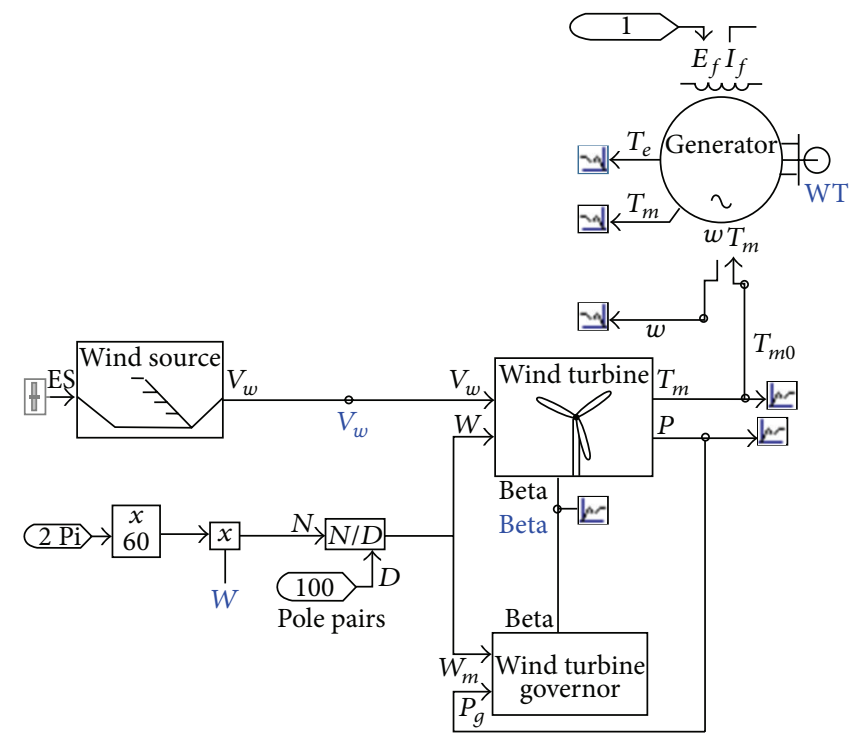

FIGURE 2: Wind turbine model in PSCAD [3].

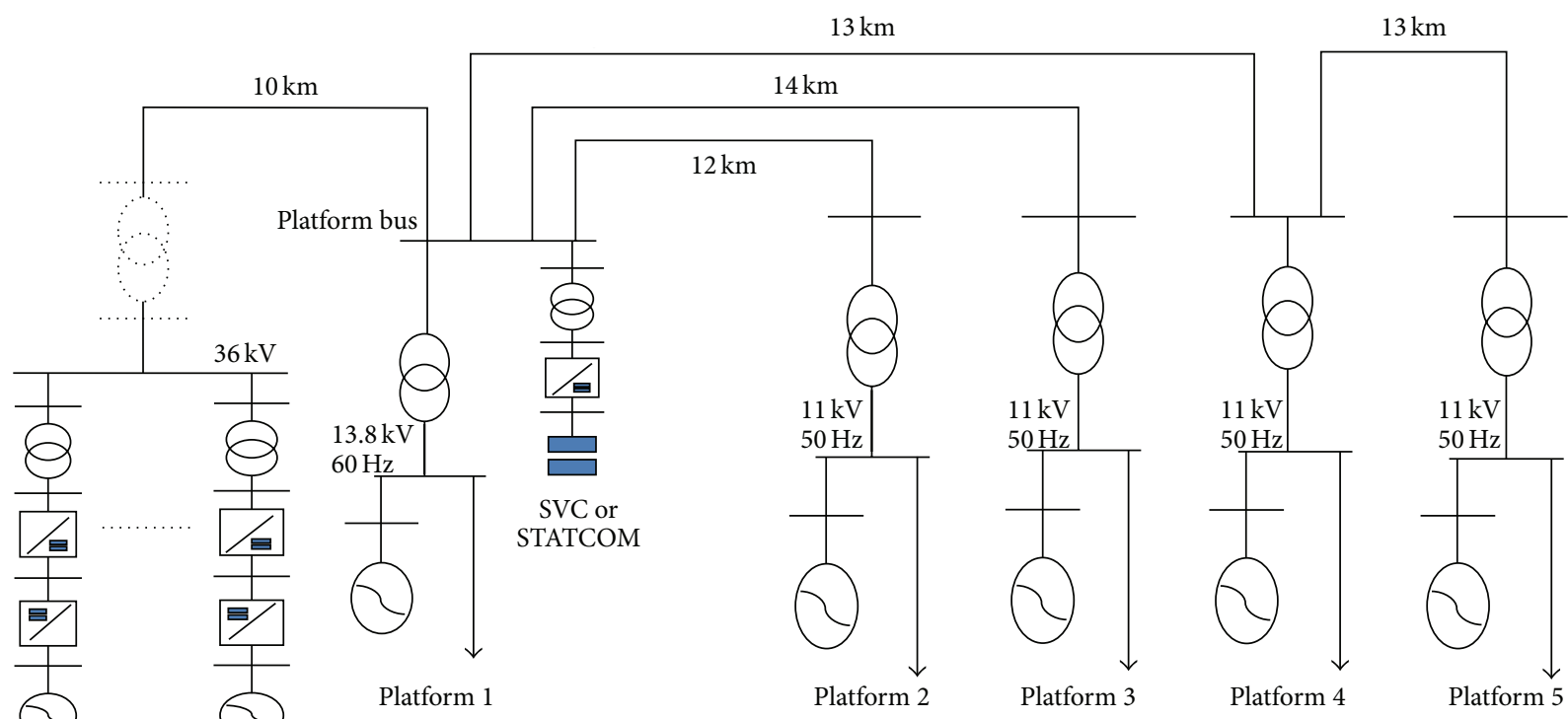

Wind farm: $20 \times 5 \mathrm{MW}$

FIGURE 3: Simplified single-line diagram of the five platforms' grid.

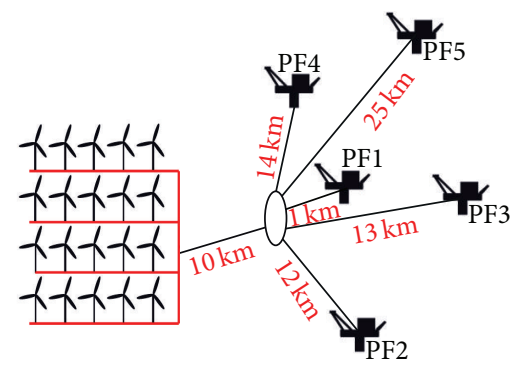

"Star"-topology

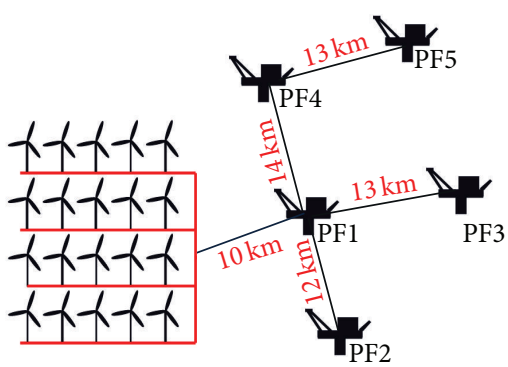

"Star-F"-topology

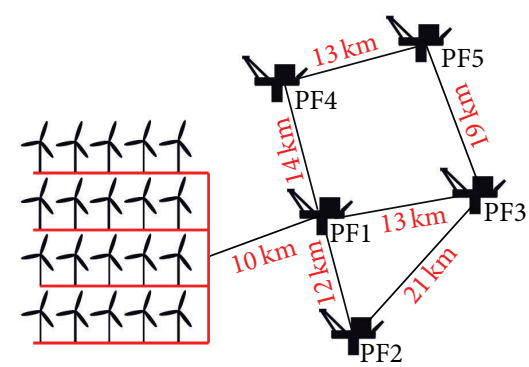

"Mesh"-topology

Figure 4: Three different interconnections of the five platforms. 
TABLE 6: Selected critical simulation cases.

\begin{tabular}{|c|c|c|}
\hline Contingency scenarios & Case & Case description \\
\hline \multirow{3}{*}{$\begin{array}{l}\text { A } \\
\text { Starting of motor }\end{array}$} & A0 & $\begin{array}{l}\text { Single platform system: starting of a } 9 \mathrm{MW} \text { motor at PF } 4,1 \text { or } 2 \text { GTs online with equal power } \\
\text { sharing }\end{array}$ \\
\hline & $\mathrm{A} 1$ & $\begin{array}{l}\text { Starting of } 9 \mathrm{MW} \text { motor at PF } 4,8 \mathrm{GTs} \text { online with equal power sharing at different } \\
\text { platforms, no wind penetration }\end{array}$ \\
\hline & A2 & $\begin{array}{l}\text { Starting of } 9 \mathrm{MW} \text { motor at PF4, } 8 \mathrm{GTs} \text { online with equal power sharing at different } \\
\text { platforms, } 100 \mathrm{MW} \text { wind penetration }\end{array}$ \\
\hline \multirow{2}{*}{$\begin{array}{l}\text { B } \\
\text { Loss of gas turbine power }\end{array}$} & B1 & Loss of a GT at PF4, no wind, and initially 9 GTs online at different platforms \\
\hline & $\mathrm{B} 2$ & Loss of a GT at PF4, $100 \mathrm{MW}$, wind and initially 9 GTs online at different platforms \\
\hline \multirow{3}{*}{$\begin{array}{l}\text { C } \\
\text { Loss of wind power }\end{array}$} & $\mathrm{C} 1$ & Loss of 25\% (25 MW) wind power, $8 \mathrm{GT}$ online with equal power sharing \\
\hline & $\mathrm{C} 2$ & Loss of $50 \%(50 \mathrm{MW})$ wind power, $8 \mathrm{GT}$ online with equal power sharing \\
\hline & $\mathrm{C} 3$ & Loss of $100 \%(100 \mathrm{MW})$ wind power, $8 \mathrm{GT}$ online with equal power sharing \\
\hline \multirow{2}{*}{$\begin{array}{l}\text { D } \\
\text { Loss of interconnection between } \\
\text { platforms PF1 and PF } 4\end{array}$} & D1 & $\begin{array}{l}\text { Loss of interconnection-PF1 and PF4, } 8 \text { GTs online with equal power sharing at different } \\
\text { platforms, with } 50 \mathrm{MW} \text { wind }\end{array}$ \\
\hline & D2 & $\begin{array}{l}\text { Loss of interconnection-PF1 and PF4, } 8 \text { GTs online with equal power sharing at different } \\
\text { platforms, with } 100 \mathrm{MW} \text { wind }\end{array}$ \\
\hline
\end{tabular}

${ }^{*}$ WT: wind turbine, GT: gas turbine, PF1-PF5: platforms 1 to 5 .

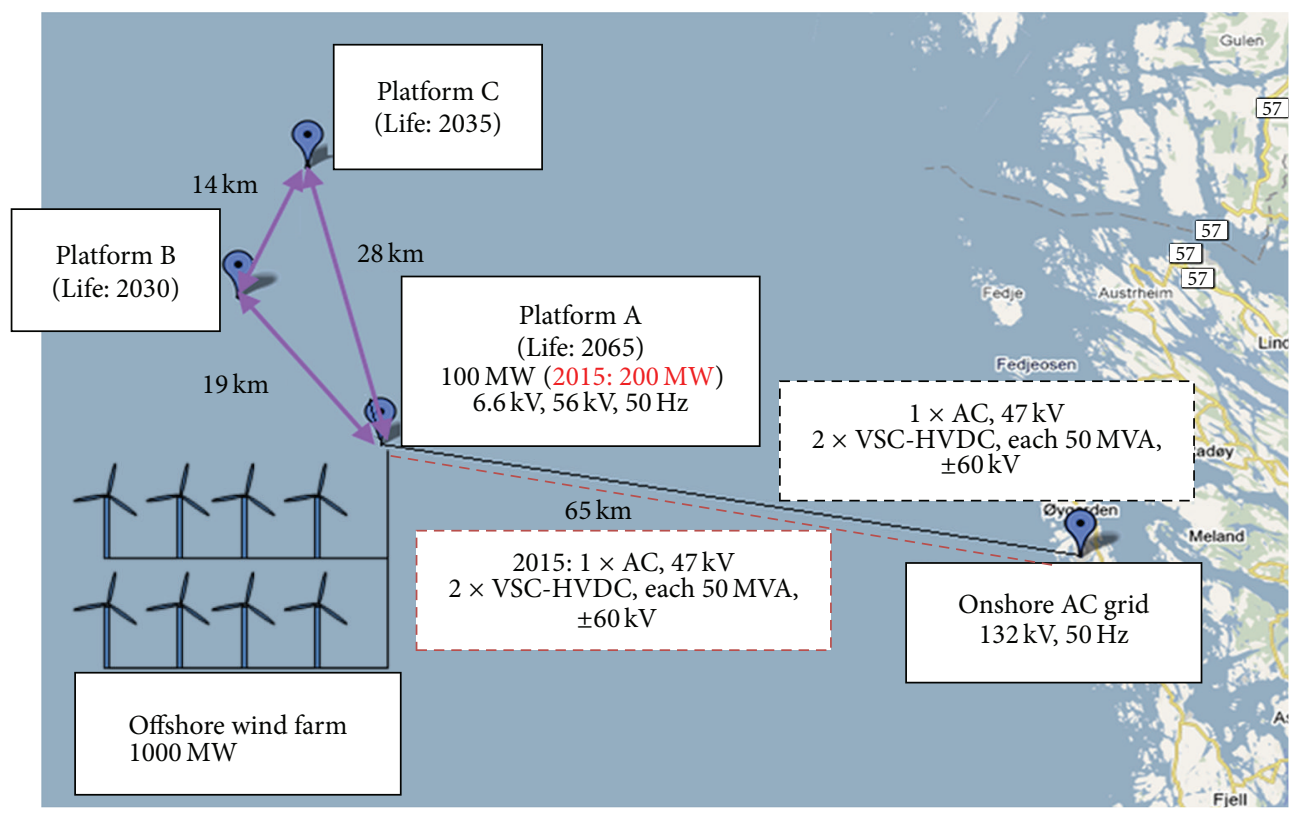

FIGURE 5: Illustration of $1000 \mathrm{MW}$ case.

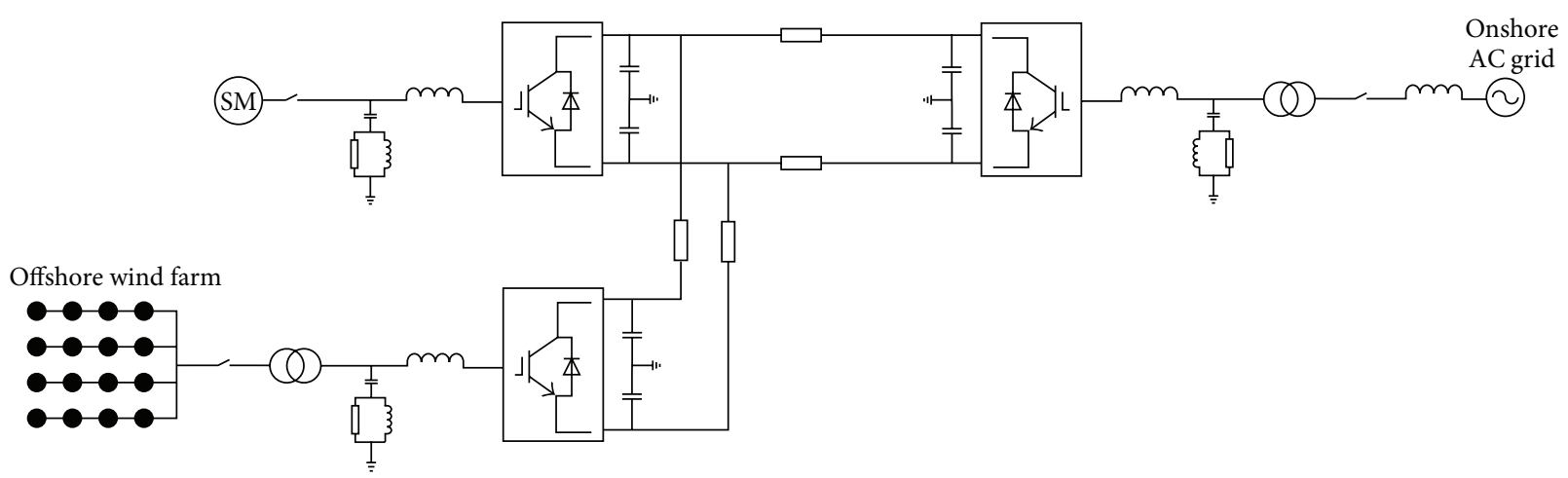

FIGURE 6: One proposal of the $1000 \mathrm{MW}$ offshore wind farm integration. 

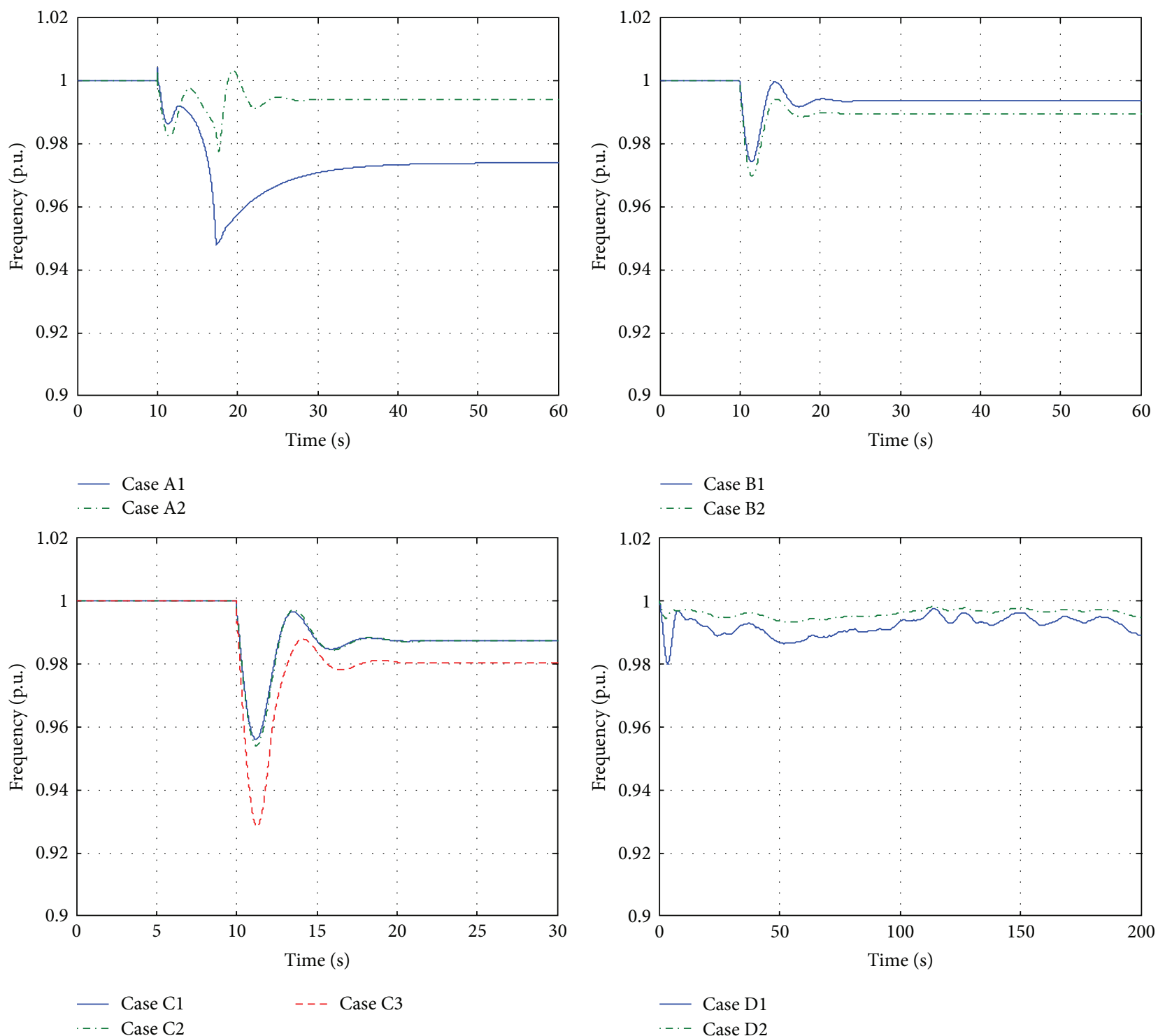

FIgURE 7: Frequency variations under transient conditions for the 9 simulation cases.

scenario was used to identify the maximum limit for wind power integration to the stand-alone electrical grid at the offshore platform.

The simulation results of the frequency and voltage variations for the nine simulation cases shown in Figures 7 and 8 can be listed as follows.

(i) The motor start resulted in a frequency variation from $+0.5 \%$ to $-1.5 \%$ and the voltage variation was $+13 \%$ to $-18 \%$.

(ii) The loss of one gas turbine resulted in a frequency variation of $-3 \%$ with the final deviation of $-1 \%$ and the voltage variation was $-4 \%$ with a final deviation of $-0.5 \%$.
The loss of all wind turbine power resulted in a frequency variation of $-7.3 \%$ and the voltage variation was $-1.7 \%$ to $5.3 \%$ under transient conditions.

The largest deviations in frequency and voltage are observed in Cases A1 and C3. The frequency and voltage deviations during loss of all wind turbines are given in Table 4 . This worst-case scenario will be used to identify the maximum amount of wind power allowable for integration to the stand-alone electrical grid on the offshore platform in the following section.

The loss of all wind power became critical when the amount of wind power integration is increased, and this scenario was used to identify the maximum limit for wind power integration to the stand-alone electrical grid at the offshore platform. 

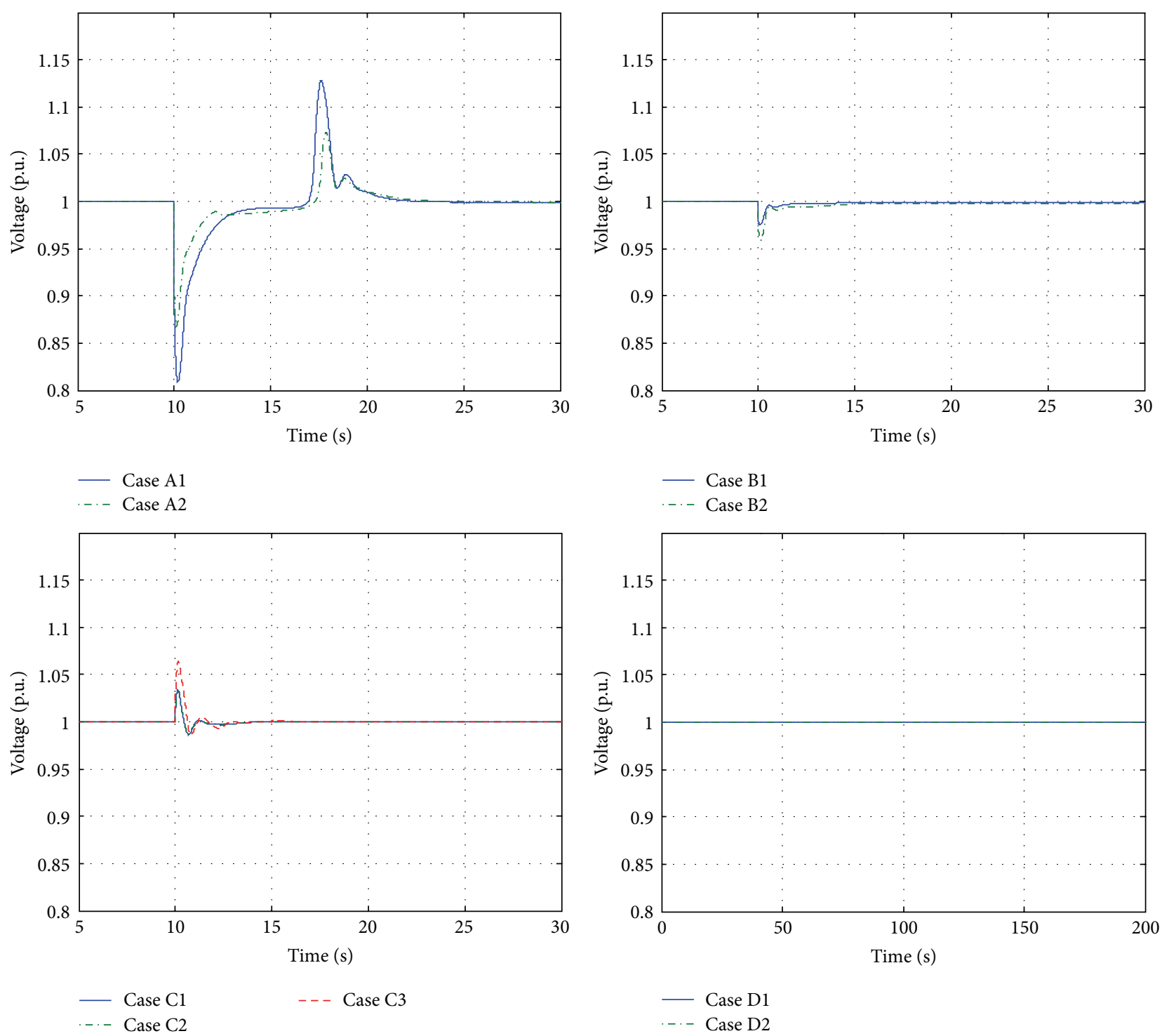

FIGURE 8: Voltage variations under transient conditions for the 9 simulation cases.

Case A0: single platform system Frequency variation comparison, staring of $9 \mathrm{MW}$ motor at PF4, $13.8 \mathrm{kV}$ system - no wind

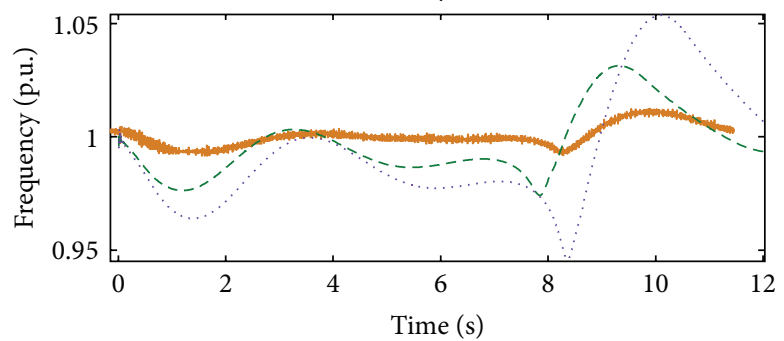

- - - Single platform system (2 GT online) Single platform system (1 GT online)
Case A0: single platform system, voltage variation comparison at load bus $\mathrm{PF} 4$, staring of $9 \mathrm{MW}$ motor at $\mathrm{PF} 4-$ no wind

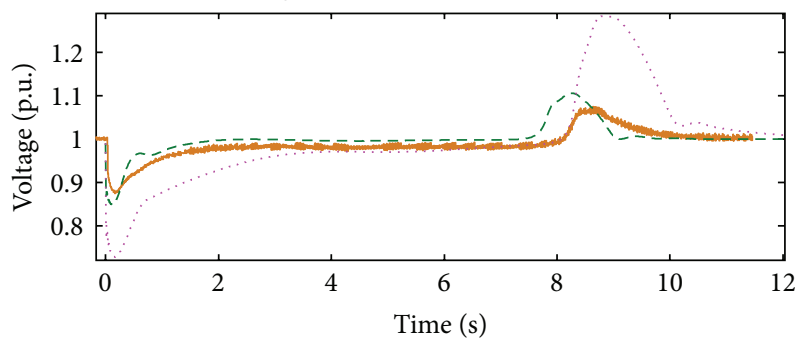

- - - Single platform system (2 GT online)

Single platform system (1 GT online)

Figure 9: Comparison of the frequency and voltage variation with the measurement data. 

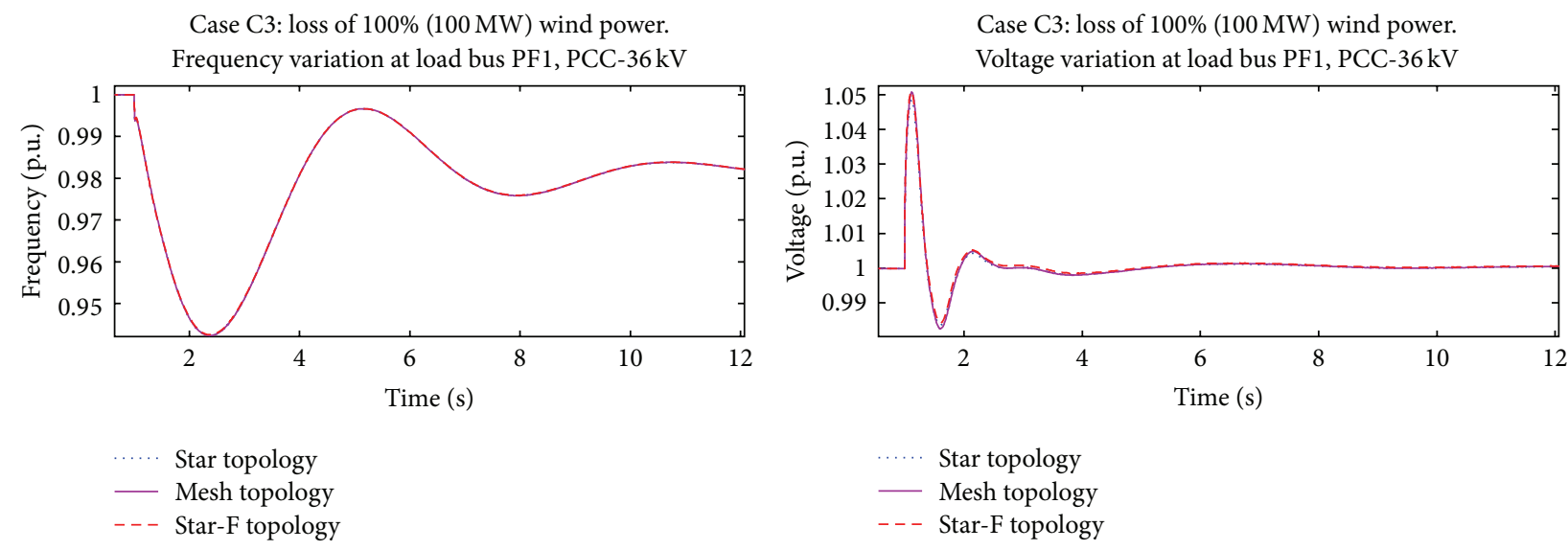

Case C3: loss of 100\% (100 MW) wind power.

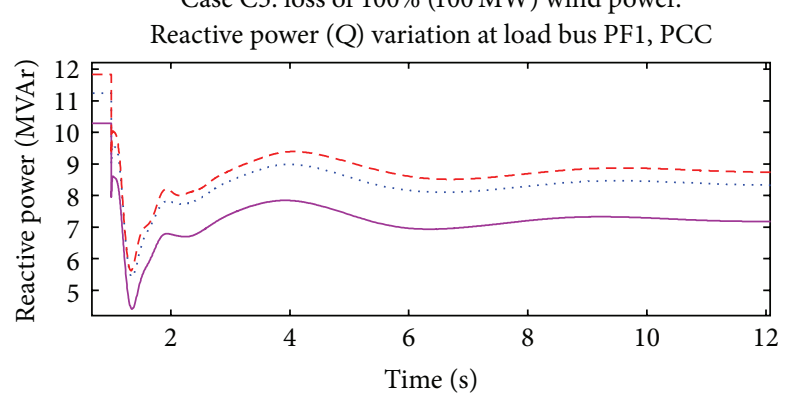

$$
\begin{array}{ll}
\text { … Star topology } \\
\text { - } \text { Mesh topology } \\
\text { - - } & \text { Star-F topology }
\end{array}
$$

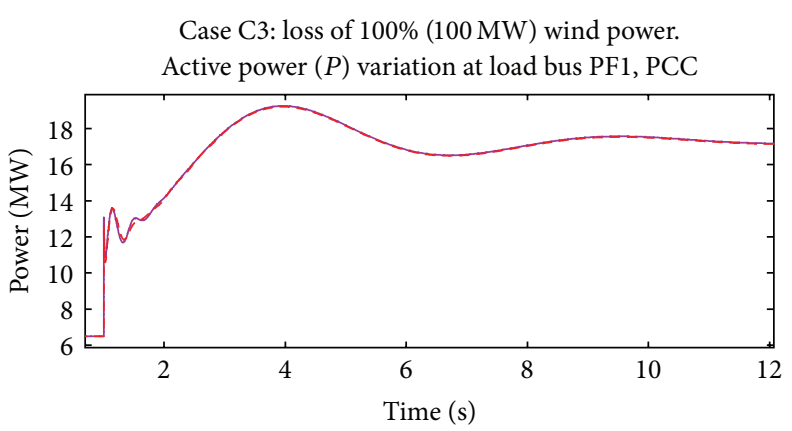

Star topology

- Mesh topology

- - Star-F topology

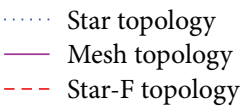

FIGURE 10: Frequency, voltage, and power variations due to loss of $100 \%$ wind power.

\section{Simulation Results of Case $2-100 \mathrm{MW}$ Wind Farm}

The first objective of $100 \mathrm{MW}$ case is to assess the maximum amount of wind power that can be integrated to each platform. The second objective is to evaluate the electrical grid stability.

5.1. Identifying the Maximum Amount of Wind Power Can Be Integrated to Each Platform. To utilize more wind power, the $20 \mathrm{MW}$ case was extended to include a $100 \mathrm{MW}$ wind farm with integration with five nearby oil and gas platforms by subsea power cables. The maximum wind power during loss of all wind power was assessed with regard to NORSOK standard of frequency and voltage variations. The calculated maximum wind power which can be integrated to each platform is listed in Table 5. The total maximum wind power of $49 \mathrm{MW}$ and $82.6 \mathrm{MW}$ could be integrated to the five platforms at low and at high load modes with regard to the governing standards concerning acceptable frequency and voltage variations. It must be noticed that there is another technical challenge in connecting the electrical grids with different frequencies of $50 \mathrm{~Hz}$ and $60 \mathrm{~Hz}$. This problem is not dealt with in the present study.
5.2. Electrical Grid Stability. In order to assess the largest transients of frequency and voltage variations of the network load buses, the four critical events are cataloged as follows.

(i) A: starting of $9 \mathrm{MW}$ induction motor at PF4.

(ii) B: loss of gas turbine at PF4.

(iii) C: loss of wind power.

(iv) D: loss of interconnection between PF1 and PF4.

The selected critical simulation cases are listed in Table 6. The simulation results of Case A0 and C3 are shown in Figures 9 and 10. Case A0 gives the comparison of the frequency and voltage variation with the measurement data. Case C3 is the most critical case which has a loss of $100 \%$ wind power.

The comparison of the frequency, voltage, and power variations due to the loss of different percentages of the wind power (with Star topology of the grid) is given in Figure 11. As expected, the simulation results show that the loss of higher percentage of the wind power production results in more variations. 

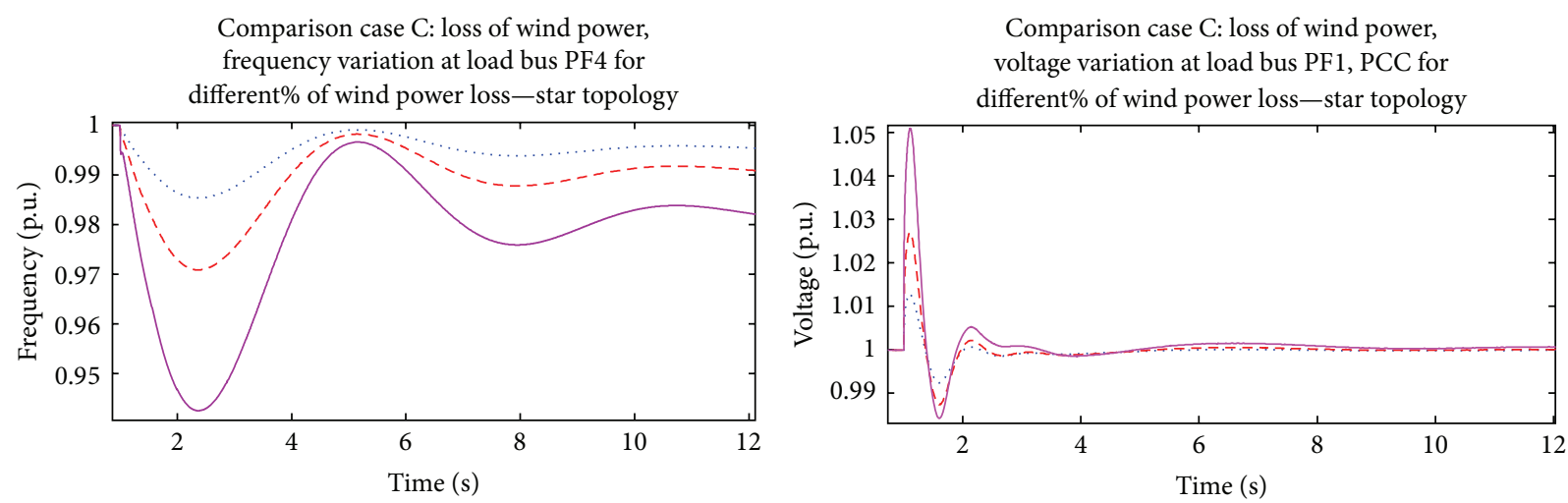

Comparison case C: loss of wind power,

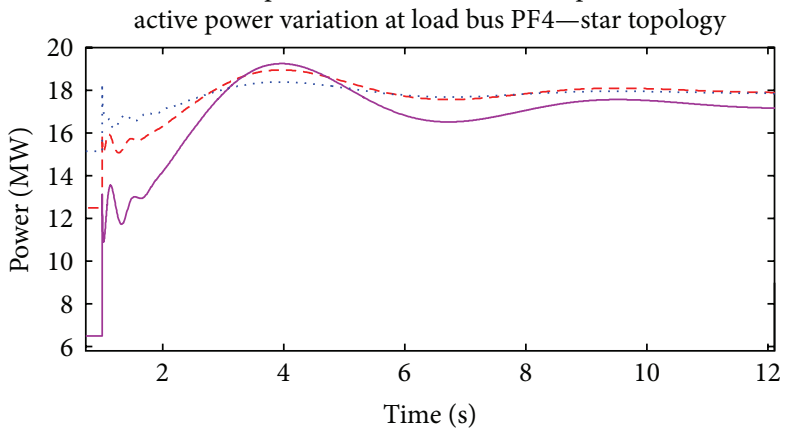

. Case C1, 25\% wind power loss

- - Case C2, 50\% wind power loss

— Case C3, 100\% wind power loss

FIGURE 11: Frequency, voltage, and power variations due to the loss of wind power.

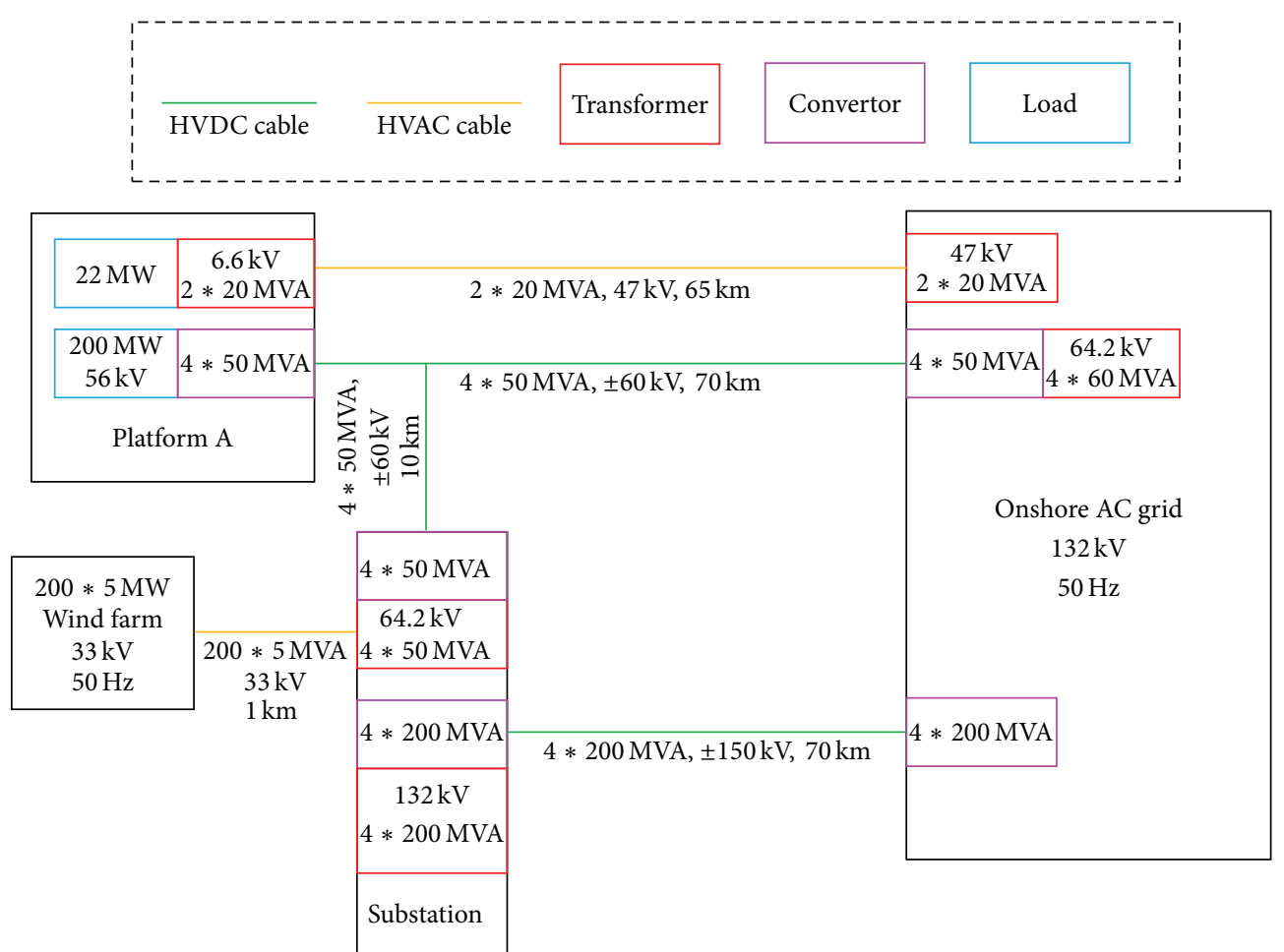

Figure 12: Proposed $1000 \mathrm{MW}$ wind farm integration electrical grid. 


\section{Simulation Results of Case 3-1000 MW Wind Farm}

In order to achieve an economically feasible offshore wind farm, a $1000 \mathrm{MW}$ wind farm was proposed for supplying wind power to both the oil and gas platforms and to the onshore electrical grid. The studied $1000 \mathrm{MW}$ case focused on the implementation aspects as follows.

(i) Design the electrical grid layout

(ii) Calculate the transmission losses

(iii) Evaluate the electrical grid stability.

A proposed $1000 \mathrm{MW}$ wind farm layout is shown in Figure 12, which is configured as multiterminal HVDC topology. The MTDC transmission system includes platform terminal, wind farm terminal, and grid terminal. As the four high voltage synchronous motors on Platform A are isolated, and the load to the compressors is required to be regulated, there are four identical HVDC transmission lines between the platform and onshore grid. Each one is $50 \mathrm{MVA}, \pm 60 \mathrm{kV}$. The $200 \mathrm{MW}$ offshore wind farm is divided into 4 parts that are linked to DC side of the platform terminal with four voltage source converters. Owing to the limited space and carrying capacity of Platform A, a separate platform to serve as the offshore substation has to be built to hold the heavy equipment, such as transformers and HVDC converter stations. There are another four VSC-HVDC transmission lines to transport the excess $800 \mathrm{MW}$ wind energy to the onshore AC grid. With reference to the review of the supplier's products, the specification is set as $200 \mathrm{MVA}, \pm 150 \mathrm{kV}$ for each VSCHVDC transmission system connecting between the offshore substation and onshore grid.

The main transmission losses of the proposed $1000 \mathrm{MW}$ wind farm integration include the loss of convertor, transformer, and cable [9], and the calculated total transmission loss was $5.24 \%$ at full load.

The electrical grid stability of the Platform A and its integration of offshore wind farm were tested by ten scenarios in four contingency cases: (1) load changes; (2) wind power fluctuations; (3) loss of wind power generation; and (4) occurrence of an onshore short circuit. The simulation results of cases 3 and 4 have been presented in [8]. In the worst case of losing all wind farm production, the simulated voltage variation of $\pm 0.3 \%$, and the frequency variation of $\pm 3 \%$ still met the requirement of NORSOK standard. During the occurrence of onshore short circuit fault, the active power generation of wind farm was reduced while the DC voltage of the MTDC system was kept in a reasonable range. When the fault is cleared, the wind farm production recovered after the transient effects.

\section{Conclusion}

Three case studies comprising wind farms rated at $20 \mathrm{MW}$, $100 \mathrm{MW}$, and $1000 \mathrm{MW}$ show that utilizing offshore wind farm for offshore oil and gas platforms and for supplying the power to onshore grid is a promising alternative to reduce $\mathrm{CO}_{2} / \mathrm{NO}_{x}$ emissions. One yearly case based on the real load data gave an annual reduction of $40 \%$ of the $\mathrm{CO}_{2} / \mathrm{NO}_{x}$ emissions. The wind power capacity could be further increased by connecting a wind farm to five nearby platforms (100 MW case) and further still by using electrical subsea cables to supply the surplus wind power to an onshore electrical grid (1000 MW case). All three cases are theoretically feasible based on this preliminary study; further studies are required to overcome many other operational, logistical, and economic problems.

\section{Acknowledgments}

The first author gratefully acknowledges Statoil's Offshore Wind Group's support to this study. The model of $100 \mathrm{MW}$ wind farm case in SIMPOW was performed under the NOWITECH (The Norwegian Research Centre for Offshore Wind Technology) program.

\section{References}

[1] OLF, Offshore renewable power for O\&G Installation, feasibility study, 2005.

[2] STRI AB, SIMPOW program manual, 2006.

[3] E. del Rio, Simulation of the wind farm integration with five oil and gas platforms [M.S. thesis], Aalborg University Semester Project Report, July 2011.

[4] NORSOK Standard E-001, Electrical Systems, 5th edition, 2007.

[5] PSCAD/EMTDC Version 3 User's Manual, Getting Started, 244 Cree Crescent, Manitoba HVDC Research Centre, Winnipeg, Canada, 3rd edition, 1998.

[6] H. Svendsen, E. Øyslebø, M. Hadiya, and K. Uhlen, "Integration of offshore wind farm with multiple oil and gas platforms," in Submitted for IEEE PES Trondheim PowerTech, Trondheim, Norway, June 2011.

[7] W. He, G. Jacobsen, T. Anderson et al., "The potential of integrating wind power with offshore oil and gas platforms," Wind Engineering, vol. 34, no. 2, pp. 125-137, 2010.

[8] G. Shi, Z. Chen, and W. He, "Grid integration of offshore wind farms and offshore oil/gas platforms," in Proceedings of IPEMC, pp. 1301-1305, 2012.

[9] N. B. Negra, J. Todorovic, and T. Ackermann, "Loss evaluation of HVAC and HVDC transmission solutions for large offshore wind farms," Electric Power Systems Research, vol. 76, no. 11, pp. 916-927, 2006. 


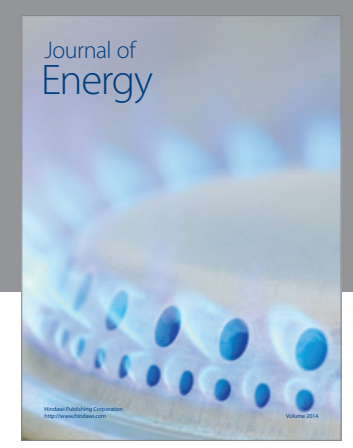

Journal of

Industrial Engineering
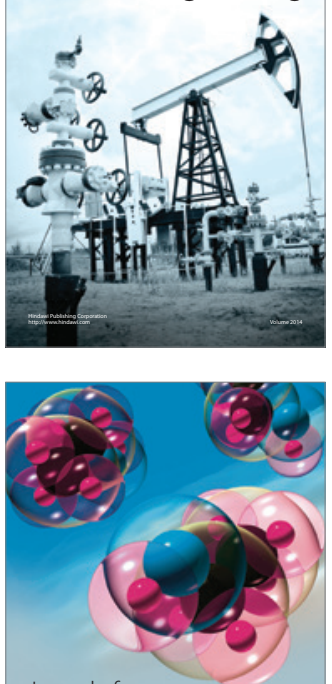

Fuels
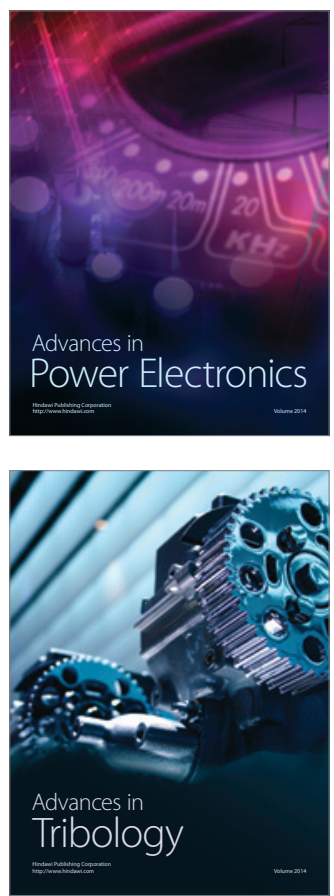

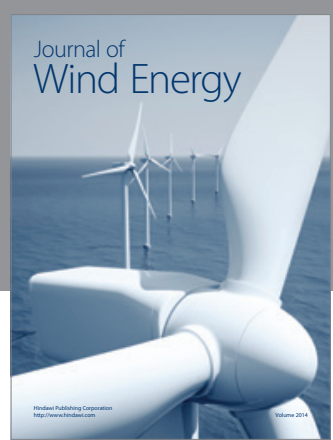

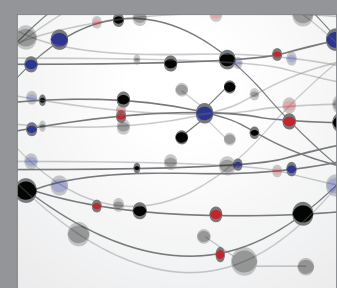

The Scientific World Journal

Submit your manuscripts at http://www.hindawi.com

Journal of

Structures
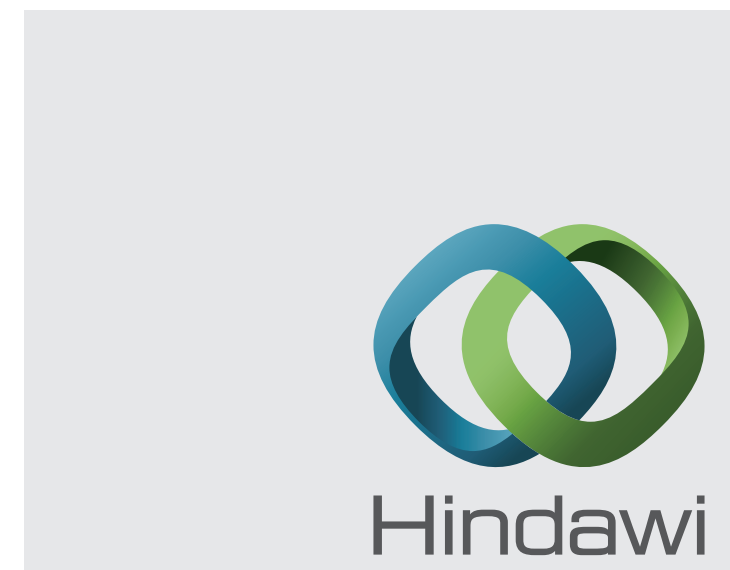

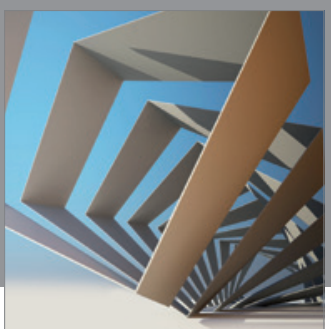

Rotating

Machinery
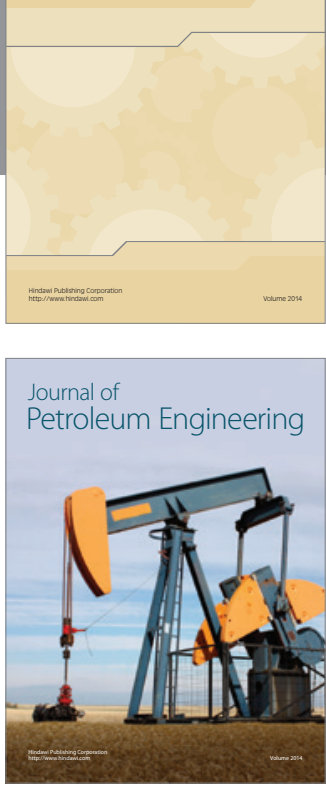

Journal of

Solar Energy
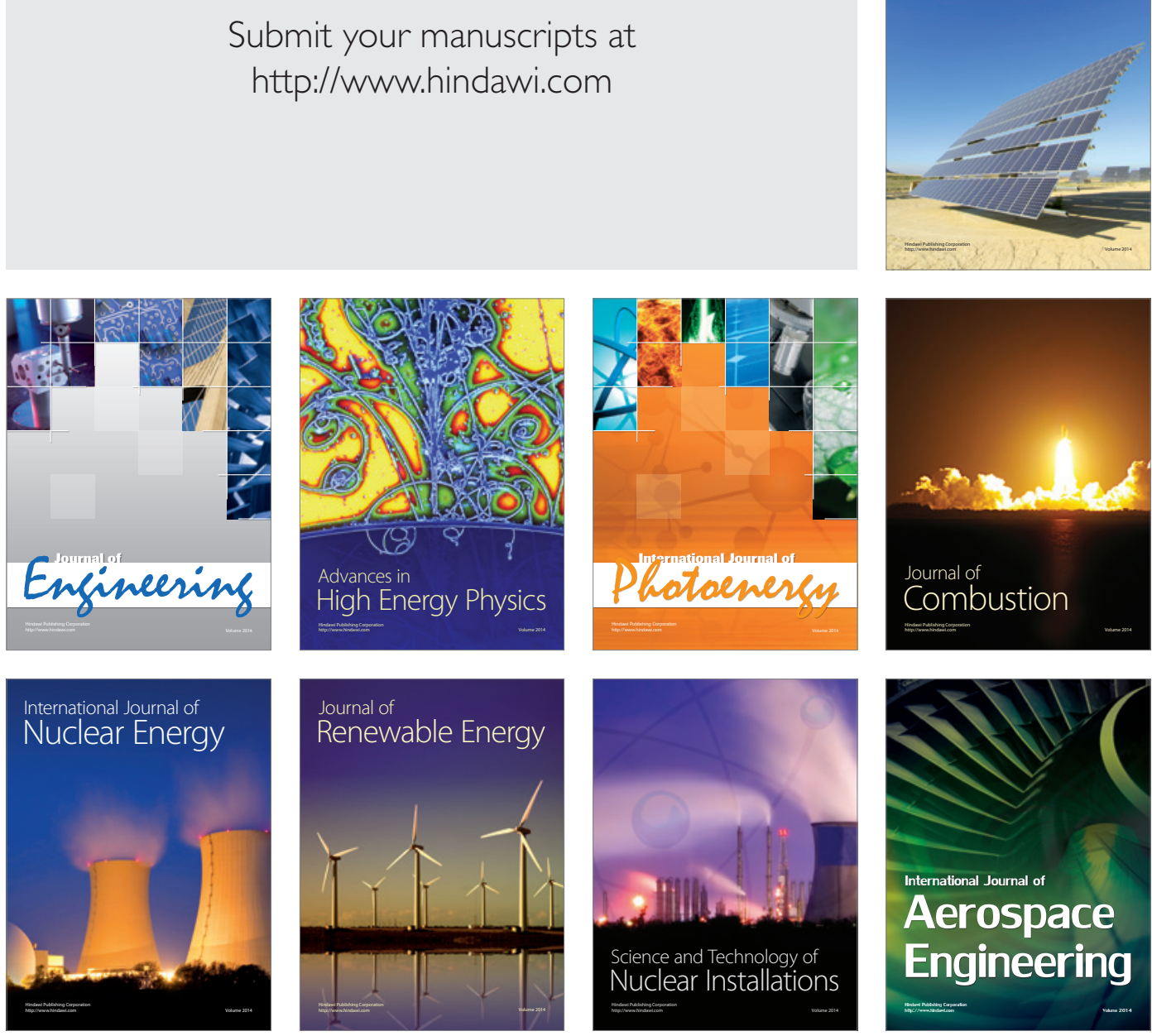